\title{
Estratégia de ensino world café: uma possibilidade de trabalhar no ensino superior
}

Simone Beatriz Reckziegel Henckes

Eniz Conceição Oliveira

Marli Teresinha Quartieri

Tania Bernhard

\section{Resumo}

Este artigo tem como objetivo analisar as contribuições da estratégia World café em uma turma de acadêmicos do curso de Ciências Biológicas Licenciatura, de uma universidade do Rio Grande do Sul. Essa estratégia foi organizada em um espaço externo à sala de aula e contou com a participação de onze acadêmicos. O estudo teve abordagem de cunho qualitativo e os instrumentos de coleta de dados foram os cartazes realizados a partir da estratégia World café. A turma foi dividida em quatro grupos e cada um recebeu uma questão norteadora para discussão e diálogo, sendo elas: (1) Como as famílias podem ser parceiras da escola na busca por um melhor aprendizado e pelo amparo das crianças e adolescentes? (2) Quais os desafios do professor de Ciências e Biologia na contemporaneidade? (3) Como as tecnologias podem contribuir para aulas mais interativas de Ciências e Biologia? (4) Explorar ou não os espaços não formais? E o que dizer dos recursos didáticos? Inicialmente, cada grupo escolheu o seu anfitrião e os demais acadêmicos foram percorrendo os outros grupos e fomentando as discussões a partir da pergunta norteadora. Na sequência, os grupos elaboraram cartazes com as sínteses definidas colaborativamente, com um feedback. A turma avaliou como positiva a estratégia, reforçando a importância de falar, escutar os colegas e construir um pensamento coletivo. Os acadêmicos também destacaram a motivação que sentiram em realizar a aula em outro espaço que não fosse a sala de aula.

Palavras-chave: Ensino Superior, Ciências Biológicas, World café. 


\title{
World café teaching strategy: a possibility to work in higher education
}

\author{
Simone Beatriz Reckziegel Henckes \\ Eniz Conceição Oliveira \\ Marli Teresinha Quartieri \\ Tania Bernhard
}

\begin{abstract}
This article aims to analyze the contributions of the World café strategy in a class of undergraduate Biological Sciences students from a university in Rio Grande do Sul. This strategy was organized in a space outside the classroom and included the participation of eleven academics. The study had a qualitative approach and the data collection instruments were the posters made from the World café strategy. The class was divided into four groups and each received a guiding question for discussion and dialogue, namely: (1) How can families be partners of the school in the search for better learning and for the support of children and adolescents? (2) What are the challenges faced by the science and biology teacher today? (3) How can technologies contribute to more interactive science and biology classes? (4) To explore non-formal spaces or not? And what about teaching resources? Initially, each group chose its host and the other academics went through the other groups and encouraged discussions based on the guiding question. Then, the groups created posters with collaboratively defined syntheses, with feedback. The class evaluated the strategy as positive, reinforcing the importance of speaking, listening to colleagues and building collective thinking. The academics also highlighted the motivation they felt in conducting the class in a space other than the classroom.
\end{abstract}

Keywords: Higher Education, Biological Science, World coffee. 


\section{Introdução}

As estratégias de ensino cada vez mais têm se destacado nas práticas de professores da Educação Básica e, da mesma maneira, têm recebido atenção no Ensino Superior. Há uma variedade de estratégias como Phillips 66, Júri Simulado, Grupo de Verbalização e Grupo de Observação (GV/GO), World café, Peer Instruction (instrução entre os pares), entre outras. Cada uma possui uma organização estrutural diferente, com características próprias. Por essa razão, é imprescindível que o professor selecione a melhor opção a ser utilizada, levando em conta alguns pontos, como número de estudantes, duração do período de aula, conteúdo, espaço físico, entre outros.

Salienta-se que as estratégias de ensino são relevantes para a prática escolar, pois são dinâmicas, atraentes e estimulam a participação e a problematização de assuntos relevantes das disciplinas. São utilizadas porque favorecem diálogos entre o professor e estudantes; podem ser desenvolvidas em espaços formais e não formais; auxiliam na construção da autonomia, no trabalho em grupo, gerando movimentos; e permitem que os estudantes assumam papel ativo na construção da aprendizagem, que vai ocorrendo durante todo o processo.

Para demonstrar como é interessante desenvolver estratégias de ensino com estudantes, na sequência relata-se uma aula no Ensino Superior desenvolvida por meio da estratégia World café. Ocorreu na disciplina Práticas de Ensino em Ciências, no curso de Ciências Biológicas Licenciatura, em uma Universidade localizada no Estado do Rio Grande do Sul (RS), e fez parte do Estágio de Docência no Ensino Superior da primeira autora. O objetivo do trabalho foi aplicar o World café e analisar suas contribuições para o ensino em uma turma do Ensino Superior a partir de perguntas elaboradas pela estagiária. A partir dessa estratégia, foi possível trabalhar questões pertinentes do cotidiano dos acadêmicos do sexto ano do referido Curso.

As perguntas foram pensadas pela necessidade de dialogar sobre assuntos já trabalhados durante aulas anteriores, mas que precisavam ser retomados. No total, foram definidas quatro questões: 1. Espaço não formal de ensino e aprendizagem; 2. Desafios dos professores na contemporaneidade; 3. Participação das famílias no contexto da escola e 4 . Tecnologias no ensino. O estudo aqui apresentado caracteriza-se como qualitativo, descritivo e possui aproximações com estudo de caso. Na sequência, apresenta-se o referencial teórico e os passos da estratégia World café.

\section{Estratégias de Ensino}

Estratégia, do grego strateegia e do latim strategi, é a arte de aplicar e explorar os meios e condições favoráveis e disponíveis, com vistas à consecução de objetivos específicos 
(ANASTASIOU e ALVES, 2003, p. 75-76). Para Bordenave e Pereira (2011, p. 134-135), existem quatro "pontos-chave" para que possa ocorrer, de forma positiva, o uso das estratégias de ensino: "1: participação ativa dos alunos, 2: escolha adequada da estratégia, 3: potencial didático diferente e 4: não há uma receita pronta e sim que haja um esforço e envolvimento do docente para a realização da estratégia”.

Como apresentado pelos autores, as estratégias não possuem uma receita pronta; há muitas variáveis a serem levadas em conta. Esses estudos evidenciam, ainda, que as contribuições do uso de diferentes estratégias para a aprendizagem dos estudantes são significativas, pois auxiliam no seu cotidiano. Como exemplo, auxiliam nas suas percepções, decisões e atitudes, seja na vida acadêmica, profissional e/ou pessoal. Na ótica de Moreira (2015, p. 3218):

[...] o aluno apresenta papel ativo diante do conhecimento que produz, podendo autogerir-se, autorregular seus comportamentos, atitudes e aprendizagens. Esta autonomia aumenta o senso de competência do educando, fazendo com que este tenha um maior envolvimento com a aprendizagem, buscando desafios.

A ideia apresentada por Moreira (2015) evidencia o papel ativo do estudante, destacando seu protagonismo na construção do conhecimento. Como protagonista, ele agrega autonomia para suas decisões e ações, de forma crítica e responsável, o que lhe permite dialogar, trocar ideias, organizar-se perante um grupo. A autonomia ajuda o estudante a entender qual é o momento de falar, de ouvir e também gera movimento. Esse movimento é no sentido de fazer o estudante participar, ajudar os colegas, ter atitudes e ser responsável. Por isso, Anastasiou e Alves (2003, p. 76) reforçam a importância do professor, afirmando que ele "é um verdadeiro estrategista, no sentido de estudar, selecionar, organizar e propor as melhores ferramentas facilitadoras para que os estudantes se apropriem do conhecimento".

Para Silva (2018, p. 206), "cabe ao professor buscar as ferramentas oportunas para atrair a atenção do aluno, despertando nele a vontade de aprender e continuar aprendendo. As estratégias são potentes, uma vez que bem planejadas". Outro ponto fundamental para o professor é estar presente de forma ativa durante o momento em que acontece a estratégia, cuidando para que os alunos não se dispersem da proposta. Deve fomentar as discussões, orientando durante o momento em que acontece a ação.

As estratégias podem ser desenvolvidas em espaços não formais, como em uma praça, área verde (lugares externos da escola/universidade) ou também em espaços formais de ensino. É oportuno destacar que em espaços não formais os estudantes sentem-se motivados, mais curiosos. Segundo Jacobucci (2008), espaço não formal é todo aquele ambiente onde pode ocorrer uma prática educativa, seja em um campo, na praça, próximo a um lago. Para 
Moreira, Vieira, Bianconi e Dias (2005), o espaço não formal desperta um maior interesse nos estudantes, pois se sentem motivados ao sair das dependências das escolas e universidades.

Um estudante motivado pela estratégia tem maior facilidade de aprender. Gil et al. (2012, p. 60) afirmam que, "quando há motivação, o professor se propõe a ensinar e o estudante se dispõe a aprender", ou seja, existe uma relação harmônica, favorecendo um ambiente tranquilo de ensino e de aprendizagem. As estratégias ajudam a melhorar as relações entre os estudantes, entre estudantes e professores e também com os funcionários das instituições. De acordo com Plácido, Schons e Souza (2017), as relações que ocorrem entre os sujeitos contribuem para a aprendizagem, pois se aprende a todo momento e com todos.

A seguir, apresenta-se, com detalhes, todas as etapas da estratégia de ensino World café que foi aplicada em uma turma do Ensino Superior no curso de Ciências Biológicas licenciatura.

\section{World café: uma rede de diálogo colaborativo}

O World café (café mundial) foi criado em meados de 1995, por Juanira Brown e David Isaacs, com intuito de fomentar diálogos mais profundos e importantes sobre temas diversos. Essa estratégia possui um formato simples, flexível, para que as pessoas possam desenvolver diálogos. Promove condições de envolvimento, participação, interação entre os participantes, visando o partilhar das ideias e a construção do conhecimento coletivo. "É um método para conversas significativas sobre questões complexas, ancorado num conjunto de princípios para criar um ambiente seguro para as pessoas falarem o que realmente importa" (FERNANDES, 2015, p. 81).

A referida estratégia, de acordo com Brown e Isaacs (2008), segue alguns princípios que são fundamentais para a aplicação e andamento do processo: 1. Determinar de forma coesa o objetivo e o assunto. 2. Organizar um espaço acolhedor, com materiais para escrita das ideias e para exposição do material, bem como café e comidas para participantes lancharem durante os debates. 3. Elaborar perguntas pertinentes, capazes de gerar argumentos relevantes. 4. Estimular a participação dos sujeitos. 5. Estimular o movimento dos alunos, ficando apenas o anfitrião no grupo para apresentar as discussões anteriores. 6. Escutar também é um princípio, pois a estratégia exige o diálogo e a escuta para a construção e significação das contribuições. 7. Após a conclusão dos diálogos, proporcionar um compartilhamento de informações ao professor e aos colegas, para que os pontos importantes discutidos possam ser socializados.

O World café possui uma sequência estrutural importante, como já citado anteriormente, pois em cada etapa acontecem ações, como junção dos grupos, momento para o diálogo, desenvolvimento das ideias, movimento, construção coletiva e, no final, elaboração de uma síntese a partir do que emergiu no decorrer das trocas (FIGURA 1). 
Figura 1: Sete passos do World café

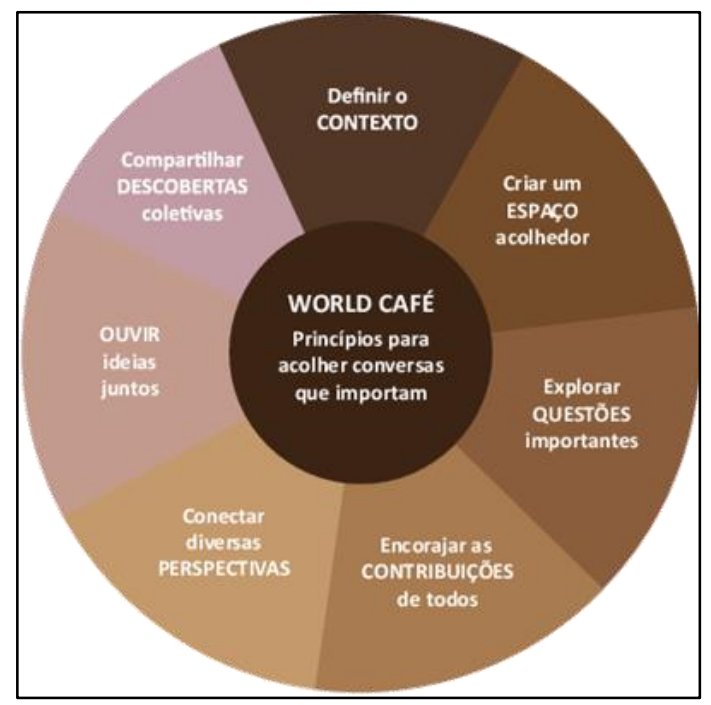

Fonte: https://www.researchgate.net/figure/Figura-1-Sete-principios-do-World-Cafe

A partir da Figura 1, descreve-se, com mais detalhes, o processo da estratégia World café, a fim de esclarecer cada etapa, seguindo do passo número 1 ao 7.

- Passo 1. Definir o contexto: é importante, para essa estratégia, que o professor tenha seus objetivos bem definidos, que saiba o que realmente pretende. Da mesma maneira, a temática precisa estar clara e coesa (HAYDT, 2006). Pode ser algum conteúdo específico ou um assunto mais amplo. O ideal é que seja um tema que os estudantes conheçam para que possam contribuir.

-Passo 2. Criar um espaço acolhedor: o espaço é fundamental para o desenvolvimento. Pode ser organizado na sala de aula, no pátio e até mesmo em um espaço não formal. O ideal é que seja em um local que tenha silêncio e que seja tranquilo, para que os estudantes não dispersem suas atenções, pois precisam estar concentrados, para, assim, partilharem suas experiências e conhecimento. O café é fundamental, pois a ideia é que a dinâmica não seja cansativa, de obrigação, mas sim, um momento leve, prazeroso. Quem organiza o "café" pode levar café, água, chá, bolo, bolachas, balas, enfim, deve pensar em um lanche para a hora da prática. O lanche pode ser organizado pelo professor ou pode-se combinar com a turma para cada um trazer um prato para compartilhar.

- Passo 3. Explorar questões importantes: as perguntas devem ser bem elaboradas, de preferência, instigantes, capazes de gerar discussões com argumentos. Deve-se evitar fazer perguntas cujas respostas sejam 'sim' ou 'não'. Para turmas da Educação Infantil, por exemplo, os professores podem explorar imagens ou pequenos vídeos com situações pontuais, visto que, nessa faixa etária, algumas crianças pequenas não são alfabetizadas. Sobre a importância das questões, Fernandes (2015, p. 168) destaca: 
[...] formular uma boa questão é uma arte, exige muito trabalho e muita atenção. As boas perguntas são essenciais para uma boa conversa, perguntas que evoquem pensamento e sentido, uma vez que estamos falando de conversas que gerem ação, perguntas que não permitam respostas prontas ou clichés.

- Passo 4. Participação de todos os integrantes do grupo. Nesse momento, o anfitrião deve estar atento, ou seja, deve perceber se os colegas estão contribuindo com o diálogo e deve instigálos a participarem. A estratégia tem como finalidade que o aluno seja ativo, isto é, que participe e contribua, fomentando cada vez mais as discussões da temática. Os participantes não devem apenas passar nos grupos olhando, escutando ou, ainda, de forma distraída, pois a estratégia requer concentração.

- Passo 5. Durante o desenvolvimento da estratégia, o ideal é que cada grupo dialogue por cerca de 10 a 20 minutos, anotando as principais ideias, pensamentos e reflexões. Após, o anfitrião permanece no grupo para que possa apresentar a discussão já realizada. Os demais seguem ao próximo grupo (FIGURA 2). Todos passam por todos os grupos, com exceção do anfitrião, que permanece todo tempo no mesmo grupo.

Figura 2: Organização dos grupos

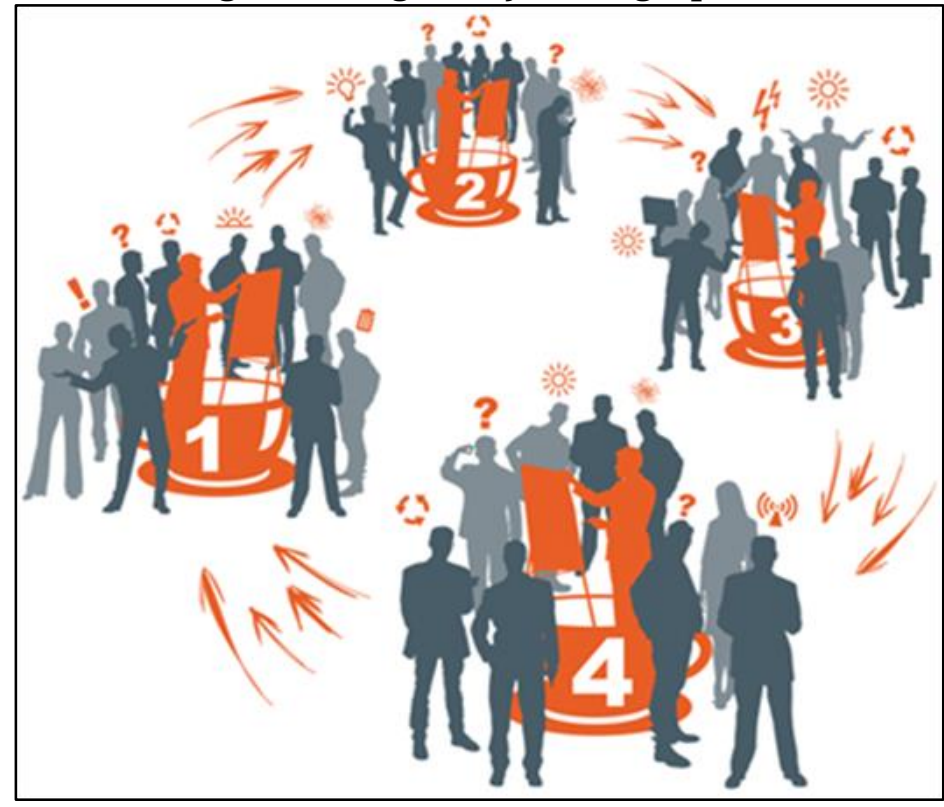

Fonte: http://icreate-project.eu/index.php?t=338

- Passo 6: Ouvir é fundamental, pois vivemos em um tempo em que muito se fala e pouco se escuta. O World café é um movimento dinâmico em que se fala, mas também se escuta.

- Passo 7: Compartilhar as ideias - passo final da sequência do World café. Nessa etapa, os participantes já dialogaram, acrescentaram conceitos, desenvolveram as argumentações. O professor poderá solicitar, aos grupos, que apresentem o que mais foi discutido e as percepções dos diálogos. Essas conclusões podem ser apresentadas por meio de cartazes 
com frases, tópicos, palavras-chave. Essa etapa é socializada pelo anfitrião, pois foi ele quem

ficou no grupo e acompanhou todo o processo.

O World café pode ser desenvolvido em qualquer nível de ensino, da Educação Infantil ao Ensino Superior; com um grupo de professores ou uma equipe de uma empresa. $\mathrm{O}$ que precisa ficar explícito é a sequência e o objetivo do trabalho. Essa estratégia proporciona um espaço dialógico que, a partir de perguntas, vídeos, imagens, pode estimular a participação das pessoas por meio de emissão de opiniões, relatos de vivências e construção coletiva de entendimento sobre um objeto que é apresentado como cerne para a discussão (BROWN; ISAACS, 2008, p. 32). Após a descrição da estratégia World café, apresenta-se a metodologia do estudo.

\section{Metodologia}

Neste trabalho foi utilizada a abordagem qualitativa. Como "proporciona melhor visão e compreensão do cenário do problema, a mesma está baseada em amostras pequenas e não representativas, os dados são analisados de uma maneira não estatística” (MALHOTRA, 2010, p. 122). Conforme Martins (2004, p. 295), esse tipo de pesquisa "levanta questões éticas, principalmente, devido à proximidade entre pesquisador e pesquisados”, preocupando-se em conhecer determinada realidade, captar seus significados e compreendê-los (TRIVIÑOS, 2002).

Para coleta de dados, solicitou-se aos acadêmicos que registrassem suas percepções nos cartazes, as quais foram analisadas por meio da Análise Textual Discursiva (MORAES; GALIAZZI, 2013) que consiste em uma reconstrução de significados, a partir da subjetividade do sujeito. Nesse sentido, é a análise que melhor se aproxima para as discussões dos dados neste artigo.

A estratégia World café foi aplicada com uma turma de onze estudantes do Ensino Superior, na disciplina Práticas de Ensino em Ciências II, no período noturno, durante o período de Estágio de Docência da primeira autora deste trabalho. Envolveu uma turma do sexto semestre, em uma Universidade localizada no Estado do Rio Grande do Sul.

\section{Descrição da prática pedagógica a partir dos passos do World café}

Durante algumas aulas na referida disciplina, os acadêmicos relatavam seus estágios de Ciências nas escolas da Educação Básica de seus munícipios. Falavam de suas angústias, dúvidas, suas práticas. Aproveitando a necessidade de expor seu trabalho para os colegas, a estagiária, já identificada como uma das autoras deste artigo, propôs utilizar uma estratégia que fosse interessante ao diálogo; nesse sentido, o World café, que tem, como objetivo, oferecer um espaço propício para dialogar com os assuntos contemporâneos. 
Para a aplicação do World café, foi organizado um ambiente externo à sala de aula, ou seja, uma área coberta bem ao centro da Universidade, com intenção de que os alunos vivenciassem uma experiência diferente. Pelo fato de a turma possuir um número reduzido de estudantes, foram organizados quatro pequenos nichos para a prática, fazendo-se uso de mesas com toalhas, cadeiras, almofadas, o que proporcionou um espaço aconchegante para os grupos dialogarem e anotarem aspectos pertinentes dos diálogos. Disponibilizou-se material para cada grupo: papel pardo, lápis de escrever, folhas coloridas, canetinhas e tesouras. O café, por sua vez, foi oferecido pela professora e pela estagiária, a fim de seguir com a proposta da estratégia.

A formação dos grupos ocorreu por meio de uma dinâmica para misturar os acadêmicos, tendo em vista as preferências já estabelecidas entre colegas. Cada um recebeu um pedaço do refrão correspondente à letra de uma música, sendo que ao total foram utilizados quatro refrãos de músicas diferentes. Cada refrão foi dividido em partes. Quando todas as partes se completassem, o grupo estaria formado. A proposta foi então explicada: cada estudante iniciaria cantando e os demais deveriam estar atentos, pois um próximo teria de continuar a música e assim até finalizar o refrão. Cabe destacar que a atividade foi bem divertida.

Na sequência, quando todos grupos já estavam constituídos, escolheram seus anfitriões e foi-lhes entregue uma pergunta, para que pudessem conversar sobre ela. Foram elaboradas quatro questões, no total, pensando-se nos diálogos paralelos que ocorriam durante as aulas. As questões foram as seguintes:

(1) Como as famílias podem ser parceiras da escola na busca por um melhor aprendizado e amparo das crianças e adolescentes?

(2) Quais os desafios do professor de Ciências e Biologia na contemporaneidade?

(3) Como as tecnologias podem contribuir para aulas mais interativas de Ciências e Biologia?

(4) Explorar ou não os espaços não formais? E o que dizer dos recursos didáticos?

No primeiro momento, os alunos mostraram-se envergonhados, mas, quando compreenderam a estratégia, foram se tranquilizando e os diálogos foram fluindo nesse momento já se mostravam ativos, mediando os diálogos e contribuindo com as narrativas, como sugere Moreira (2015). Destaca-se que foi a primeira vez que essa turma realizou a estratégia World café. Nenhum dos acadêmicos conhecia como de fato era organizada e nem a proposta real da sequência estabelecida. Durante os diálogos, os acadêmicos foram degustando o lanche. Foi solicitado, uma semana antes, que trouxessem uma caneca para tomar o café. Foi-lhes oferecido bolo, salgadinho, bolachas, balas, além do café, chá e água. O café faz parte da estratégia (BROWN; ISAACS, 2008).

O tempo aproximado para lerem a pergunta, dialogarem sobre ela e anotarem os principais tópicos e ideias foi de 15 minutos. Esse tempo foi suficiente, pois como eram grupos 
pequenos, foi possível cada integrante expor sua opinião. Após, o anfitrião permaneceu no grupo e os demais seguiram para o próximo grupo, contribuindo, assim, com as outras temáticas. Todos conseguiram, sem nenhuma dificuldade, desenvolver as etapas da estratégia.

O último passo, que consiste em compartilhar com o grande grupo o que foi feito ao final da sequência das trocas de grupos, discute-se com detalhes na sequência, pois, até aqui, demarcou-se como ocorreu o processo.

\section{Resultados}

A dinâmica da estratégia possibilitou um tempo adequado para os diálogos e trocas dos grupos, sendo que no final aconteceu o feedback dos acadêmicos, da professora titular e da estagiária. Dessa forma, “o aprendente sente-se responsável por sua aprendizagem apresentando iniciativa diante daquilo que aprende demonstrando qualidade motivacional (envolvimento com as atividades propostas)” (MOREIRA, 2015, p. 3218).

Cada grupo, após as contribuições, organizou uma síntese sobre a questão recebida. O grupo 1, cuja pergunta foi "Como as famílias podem ser parceiras da escola na busca por um melhor aprendizado e amparo das crianças e adolescentes?”, sintetizou a resposta com a seguinte frase: "o amor, o carinho e a atenção são a base de tudo". O grupo, no momento da apresentação, comentou que os sentimentos de amor, carinho e atenção são mais importantes e indispensáveis para as crianças e adolescentes do que bens materiais. Ademais, afirmaram que percebem, em suas realidades, muitos casos de crianças que não são alvos desses sentimentos; são deixadas nas escolas durante o dia e, no turno da noite, sequer são questionadas sobre como passaram o dia.

A partir dos sentimentos é possível, aos pais, dialogar com os seus filhos, incentivando-os ao estudo e acompanhando o seu desenvolvimento por meio da participação em reuniões e conversas com os professores. Lembrando que essas explanações são frutos não somente do grupo 1, mas de todos que passaram e foram contribuindo. Essa questão foi pensada para que pudessem perceber que o professor precisa ter um olhar amplo e notar a importância das famílias na construção da aprendizagem e que os sentimentos fazem parte do cotidiano de sala de aula.

Essas discussões só foram possíveis por causa da estratégia World café. Nesse sentido, ressalta-se a importância de os acadêmicos dialogarem antes mesmo de atuarem nas escolas, favorecendo um amadurecimento e potencializando suas formações. Segundo Brown e Isaacs (2008), as estratégias visam a um espaço dialógico que, por meio de perguntas, estimule a participação das pessoas na emissão de opiniões e a construção coletiva de entendimento sobre um objeto que é apresentado como cerne para a discussão.

O momento de diálogo sempre é importante, pois há trocas de saberes e experiências. A Figura 3 mostra o momento em que a estagiária e os acadêmicos dialogavam. Destaca-se, 
ainda, a necessidade do tempo para saber escutar os colegas, visto que havia, entre os participantes, alguns mais tímidos, que geralmente ficavam mais calados durante as aulas; nesse dia, puderam compartilhar suas vivências do dia a dia.

Figura 3. Grupo durante o diálogo

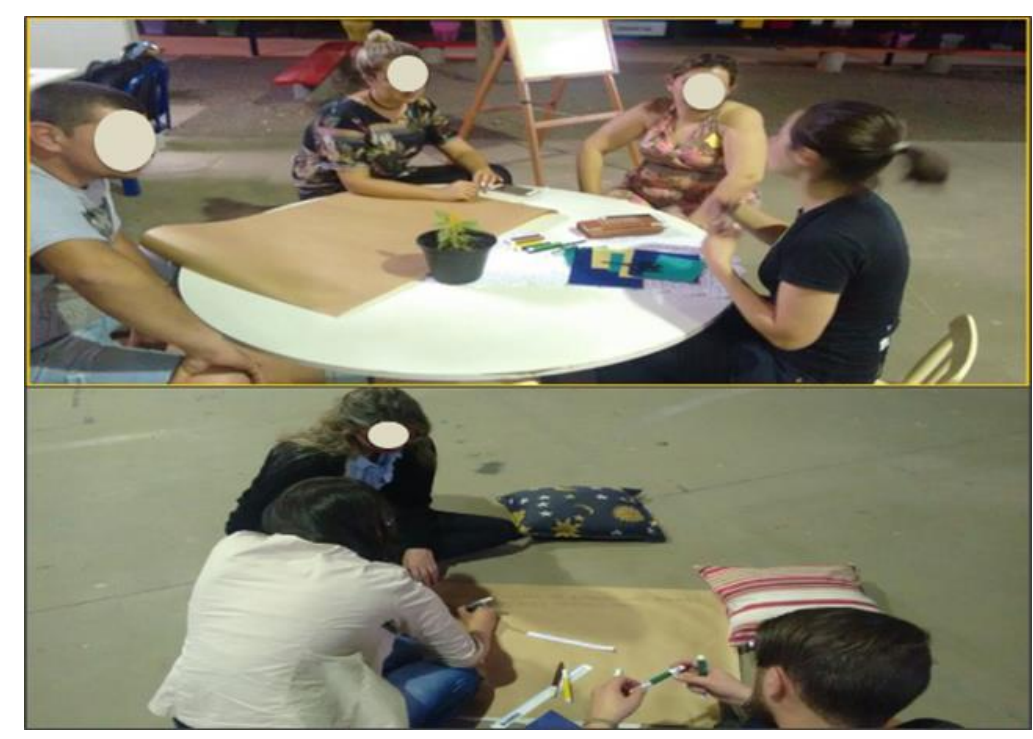

Fonte: autores (2017)

A Figura 3 mostra dois grupos no momento das discussões, em que o papel pardo foi disponibilizado juntamente com lápis, canetinha, réguas... Os acadêmicos tiveram toda autonomia para desenvolver suas anotações. Na percepção de Fernandes (2015), a participação de todos é fundamental, pois a sabedoria está na colaboração do grupo - essa é a real essência do World café.

A pergunta para o segundo grupo foi "Quais os desafios do professor de Ciências e Biologia na contemporaneidade?". Os acadêmicos destacaram que o maior desafio é "formar seres mais pensantes". Explicaram que desejam estudantes mais críticos e comprometidos com a sociedade, e não pessoas mecânicas. Analisando esta escrita, entende-se que os acadêmicos já sentem a necessidade de trabalhar de maneira mais contextualizada com o mundo. Ou seja, apenas repassar os conteúdos é quase descartado dessa visão. Citam "seres mais pensantes" e isso é imprescindível para uma alfabetização científica, que tem como princípio um olhar mais profundo de mundo (CHASSOT, 2017).

Outra questão foi "Como as tecnologias podem contribuir para aulas mais interativas de Ciências e Biologia?” Essa pergunta surgiu na turma, durante os estágios, pois comentaram que sentiam falta de trabalhar com tecnologias no Ensino Superior e tinham a plena consciência de que era um fator com que iriam se deparar nas escolas, uma vez que a geração contemporânea é da era tecnológica. O registro feito no cartaz foi: "utilização de métodos, técnicas e recursos acessíveis e relevantes aos estudantes, à escola e à aprendizagem, visando à integração dos alunos entre si e com os professores”. 
Segundo Oliveira, Gandini e Delgado (2016, p. 41), "para despertar os alunos para a aprendizagem, os professores devem buscar cada vez mais novidades e mudar sua forma de abordagem diante das novas tecnologias, pois a velha metodologia já se tornou obsoleta e desmotivadora”. Desse modo, é importante pensar nas tecnologias, a fim de potencializar o ensino das crianças e adolescentes, pois, como já mencionado, vivemos em uma era tecnológica e os professores devem incluir as tecnologias nos seus planejamentos de aulas e não excluí-las, como vem acontecendo.

A última questão foi "Explorar ou não, os espaços não formais? E o que dizer dos recursos didáticos?”. Essa pergunta teve o intuito de levar os alunos a pensarem como os espaços externos das escolas, como exemplo, o museu, o zoológico, a praça da cidade, contribuem para as aulas de Ciências e Biologia. A Ciência não precisa ser trabalhada apenas no espaço da escola (formal), mas sim, deve ser trabalhada na prática, vivenciando o que de fato acontece. Nesse sentido, a turma registrou que "é criativo explorar os espaços não formais, utilizando diversos recursos didáticos que tenham objetivos bem elaborados pelo professor para que se conquiste maior interação entre os estudantes e melhora na relação com o professor”. Os recursos didáticos e as aulas em espaços não formais agregam e potencializam a aprendizagem dos alunos, podendo-se dizer que são complementos necessários das aulas consideradas tradicionais. Para Gohn (2006), além do aprender, os espaços possibilitam a emergência de relações.

A partir da escrita realizada pelos acadêmicos, percebeu-se que a estratégia foi significante por desenvolver a escrita colaborativa e, ao mesmo tempo, a integração nos grupos. Segundo Anastasiou; Alves (2003, p. 82), "habilidades de trabalhos grupais, devidamente desenvolvidas, auxiliam no desabrochar da inteligência relacional”. Também foi possível perceber que a estratégia ajudou nas falas e escutas, visto que todos participaram. No final da aula, os acadêmicos agradeceram pela oportunidade de uma aula diferente, que conseguiu envolver a turma. Destacaram como positiva a aula com a estratégia World café, sem deixar de falar que acharam muito criativo ter o café durante as discussões, o que auxiliou na concentração e sequência, pois não houve necessidade de realizar o intervalo.

\section{Considerações finais}

As estratégias de ensino são importantes para os professores alcançarem seus objetivos, rompendo com a ideia de que o professor apenas transfere o conhecimento. Elas permitem que o estudante participe de forma ativa no desenvolvimento do seu processo cognitivo. Assim, as aulas tornam-se mais dinâmicas, atrativas, motivadoras e colaborativas. Nesse contexto, o professor tem a função de mediar e provocar, inovando sua própria prática, para que ocorra o aprofundamento das discussões e o estudante vá além do senso comum. 
As quatro perguntas elaboradas foram pensadas a partir do contexto de sala de aula durante o estágio no Ensino Superior, sendo questões pertinentes para a realidade dos acadêmicos; portanto, houve discussões em todos os grupos. $\mathrm{O}$ anfitrião permaneceu na sua temática e foi conduzindo os diálogos. Os acadêmicos sentiram-se confortáveis com o espaço organizado e acharam divertido e pertinente ter lanches à disposição, saindo do método tradicional a que estavam acostumados na sala de aula.

Cabe salientar que a aplicação da estratégia World café auxiliou na elaboração de ideias construídas pela coletividade dos acadêmicos, colaboração do conhecimento. Explorar um outro espaço também foi importante e motivador, moorlstrando a possibilidade de sair do contexto da sala de aula, sem prejudicar a proposta de trabalho; pelo contrário, motivando cada vez mais os acadêmicos para a aprendi ocorrendo zagem. Enfim, a estratégia World café pode ser trabalhada no Ensino Superior, principalmente em turmas de licenciaturas, cujos acadêmicos, futuramente, estarão nas escolas e poderão desenvolver um trabalho diferenciado com seus alunos, mostrando a importância de participar, de ser protagonista e colaborativo.

\section{Referências}

ANASTASIOU, L. G. C.; ALVES, L. P. (Orgs). Processos de Ensinagem na Universidade: Pressupostos para as estratégias de trabalho em aula. São Paulo: Univele, 2003.

BORDENAVE, J. D.; PEREIRA, A. M. Estratégias de ensino-aprendizagem. 31. ed. Petrópolis: Vozes, 2011.

BROWN, J.; ISAACS, D. The World Cafe: Shaping Our Futures Through Conversations That Matter. São Francisco, California: Berrett-Koehler Publishers, 2005.

BROWN, J.; ISAACS, D. O World Café: dando forma ao nosso futuro por meio de conversações significativas e estratégicas. São Paulo: Cultrix, 2008.

CHASSOT, A. Alfabetização científica: questões e desafios para a educação. 7. ed. Ijuí: Ed. Unijuí, 2017.

FERNANDES, M. E. S. A. C. O World café e o aprendizado pelo diálogo: limites e possibilidades de um território de sentidos no processo de formação "Diagnóstico socioambiental na APA Embu Verde: Educação ambiental para a sustentabilidade na bacia do rio Cotia” Embu das Artes, SP. 2015. 210 f. Tese (Doutorado-Programa de Pós-Graduação em Educação) - Faculdade de Educação da Universidade de São Paulo, São Paulo, 2015. 2015.

GIL, E. S.; GARCIA, E. Y. A.; LINO, F. M. A; GIL, J. L. V. Estratégias de ensino e motivação de estudantes no ensino superior. Vita et Sanitas, Trindade, n. 06, jan-dez. 2012. Disponível em: http://fug.edu.br/revista/index.php/VitaetSanitas/article/view/51. Acesso em: 01 de ago. 2019. 
GOHN, M. da G.. Educação não-formal, participação da sociedade civil e estruturas colegiadas nas escolas. Ensaio: Avaliação e Políticas Públicas em Educação, 2006, vol. 4, n. 50.

HAYDT, R. C. C. Curso de didática geral. São Paulo: Ática, 2006.

JACOBUCCI, D. F. C. Contribuições dos espaços não formais de educação para a formação da cultura científica. Em extensão, Uberlândia, v. 7, 2008.

MACHADO, M. P. M.; PASSOS, M. F. D. O uso do World café como método de pesquisa junto às equipes de saúde. Revista Brasileira em Promoção da Saúde, 31(Supl): p. 110, nov., 2018.

MALHOTRA, N. Pesquisa de marketing: foco na decisão. 3 ed. São Paulo: Pearson, 2010.

MARTINS, H. H. S. Metodologia qualitativa de pesquisa. Rev. Educação e Pesquisa. São Paulo, v.30, n.2, p. 289-300, maio-ago. 2004. Disponível em: < http://www.scielo.br>. Acesso em: 13 out. 2017.

MORAES, R.; GALIAZZI, M. C. Análise textual discursiva: processo construído de múltiplas faces. Ciência e Educação, v. 12, n.1, 2006.

MOREIRA, A.; VIEIRA, V.; BIANCONI, L.; DIAS, M. Espaços não-formais e o currículo de ciências. Ciências e cultura, v. 57, n. 4. São Paulo, 2005.

MOREIRA, A. E. C. A importância do ensino das estratégias de aprendizagem aos alunos do ensino fundamental. In: Anais XII Congresso Nacional de Educação, p. 32163228, 2015.

OLIVEIRA, A. P. M.; GANDINI, L. C. R.; DELGADO, O. O. C. Novas tecnologias na educação: desafios e perspectivas no processo de ensino-aprendizagem. Revista Espaço Acadêmico, v. 5, n. 10, 2016. Disponível em: https://multivix.edu.br/wp.content/uploads/2018/06/revista-espaco-academico-vo5-n1o-artigo-3.pdf Acesso em: 25 jul. 2019.

PLACIDO, R. L.; SCHONS, M.; SOUZA, M. J. C. S. Utilização das estratégias de ensinoaprendizagem na educação profissional e tecnológica. Revista Dynamis, Blumenau, v. 23, n. 1, p. 40-57, 2017.

SILVA, J. F. Didática no Ensino Superior: estratégias de ensino adequadas à arte de ensinar.

Educação por escrito, Porto Alegre, v. 9, n. 2, p. 204-219, jul.-dez. 2018. Disponível

em:http://revistaseletronicas.pucrs.br/ojs/index.php/porescrito/article/view/31275 /17595. Acesso em: 10 de jul. 2019.

TRIVIÑOS, A. N. S. Introdução à pesquisa nas ciências sociais. São Paulo: Atlas, 2002. 


\section{agradecimento}

O presente trabalho foi realizado com apoio da Coordenação de Aperfeiçoamento de Pessoal de Nível Superior - Brasil (CAPES) - Código de Financiamento o01.

\section{Biografia Resumida}

Simone Beatriz Reckziegel Henckes: Doutoranda e mestre em Ensino pela Universidade do Vale do Taquari - Univates. Bolsista integral PROSUC/CAPES.

Lattes: http://lattes.cnpq.br/0189864425847536

Contato: simone.henckes@universo.univates.br

Eniz Conceição Oliveira: Doutora e Mestre em Química pela Universidade Federal do Rio Grande do Sul - UFRGS. Pósdoutorado pelo Departamento de Educação e Psicologia da Universidade de Aveiro (UA) em Portugal. Professora dos Programas de Pós-graduação em Ensino e Ensino de Ciências Extas na Universidade do Vale do Taquari - Univates.

Lattes: http://lattes.cnpq.br/2058979202735427

Contato:eniz@univates.br

Marli Teresinha Quartieri: Doutora em Educação pela Universidade Vale do Rio dos Sinos - RS, Mestre em Matemática Aplicada pela Universidade Federal do Rio Grande do Sul UFRGS. Professora dos Programas de Pós-graduação em Ensino e Ensino de Ciências Extas na Universidade do Vale do Taquari - Univates.

Lattes: http://lattes.cnpq.br/o483754754945290

Contato: mtquartieri@univates.br

Tania Bernhard: Mestre em Educação pela Universidade Federal de Santa Maria/RS. Professora dos cursos Ciências Biológicas Bacharelado e Licenciatura na Universidade de Santa Cruz do Sul - UNISC.

Lattes: http://lattes.cnpq.br/1182369240814717

Contato: btania@unisc.br 